\title{
The practice and innovation of computer application technology in private colleges and universities
}

\author{
Yan Zhang \\ Jiangxi Institute of Software Engineering, China
}

Keywords: private colleges, computer application technology, innovation

\begin{abstract}
With the rapid development of computer application technology, computer course teaching is faced with some problems. Currently, in view of the insufficient teaching means which aim to the characteristics and the training of computer application skills of private colleges and universities students, however, this paper explores how to improve the computer application technology ability of students in private colleges and universities, and summarizes the teaching mode and teaching method which are suitable for them. It is expected to provide some innovative reference for the computer application technology practice in related colleges and universities.
\end{abstract}

Private colleges and universities have been developing rapidly in recent years and have gradually become an important part of education in China. The teaching quality of it also has always been a matter of great concern to the society. Computer application technology is the required basic course of any major in colleges and universities which is both well in the theory and the practice. Through the course of practice, students can deepen their understanding of book knowledge, enhance their perceptual knowledge, solve difficult problems in theory learning, and improve their operational ability. Therefore, the practice course is an indispensable part and important link to cultivate students' computer skills, which provides students with a chance to combine theory with practice. With the progress of science and technology and education level, the old practical ideas, which is mainly demonstrated and verified cannot keep up with the requirements of the times. This kind of way that just hands-on operation by teachers and students watch, or with the ready-made experimental results to verify whether a theory is correct or not, and collate it into an experimental report, so that students are just walking around, they do not have a good integration into the experimental environment, and did not get the experimental results as well. Therefore, to make a good practice class and truly improve the quality of practice is not only a requirement for the administrators and students of the computer room, but also a problem that teachers should think about.

\section{Analysis of the current situation of computer application technology practice teaching in private colleges and universities}

There are many researches on computer practice teaching in colleges and universities in China, which are either for public institutions or vocational institutions, but it is rare to discuss the practical teaching of computer application technology in private colleges. For a long time, the teaching of computer practical courses is influenced by the traditional education model, which emphasizes the teaching of teachers and the passive acceptance of students. With the introduction and promotion of the new curriculum reform, it is obviously not in line with the development of the times and not conducive to the comprehensive development of students. The reasons are as follows:

First, the computer knowledge level of students enrolled in school varies greatly. As computer courses are not included in the examination subjects of the college entrance examination, most middle schools do not pay attention to computer teaching. Students from big cities generally have the ability to operate computers, such as multimedia operation, the use of office software, and even some students can design programs. But for the majority of students from small cities or rural areas have taken a few or even no computer courses. 
Second, the lack of understanding of the importance of practical teaching. China's private colleges and universities are just on the right track, and there is no supporting system to be introduced in time, while the society still has doubts about the status of private colleges and universities, and insufficient understanding of the teaching characteristics of private colleges and universities. At present, the computer theory course is mostly taught in large classes, while the teacher of the experiment course is the teacher of the theory course. The average time for each student to get the guidance from the teacher is less than two minutes, and there is a lack of experimental equipment and staff.

Thirdly, the teaching methods and contents are lagging behind. As the experimental content of computer course needs to be attached to the theoretical teaching in class, while the content of the practical course mainly focuses on the application of the theoretical knowledge in the textbook, thus forming an effective supplement and assistant to the theoretical teaching, but the means and methods in the practical link are lagging behind. In the process of practice, the students just follow the experimental content and the method in the experimental instruction book formulated by the teacher to demonstrate step by step. As a result, the students only know what they know and don't know why in the process of experiment.

Fourthly, it is lack of scientific and reasonable teaching assessment measures and standards. To a large extent, the current practical courses do not conduct independent assessment separately, but still use the reflection of paper grade to assess students' performance. At the same time, teachers' evaluation of students' comprehensive quality is mainly based on the scores of theoretical courses and students' performance in the teaching process. In addition, the performance assessment method of some practical courses is based on the experimental report in the process of practice, but no certain standard. In this way, students and teachers form a problem that only values theoretical learning but not practical links, and finally practical teaching becomes a mere formality.

\section{Innovation and reform plan of practical teaching}

\subsection{Inovation and reform of teaching content}

The difference of college students' computer ability mostly reflects on the computer operation ability. As the students from the same university and different schools from different regions, there is a big difference in the computer operation ability. It can be fall into three categories generally:

First, the primary users of a computer. This kind of students master simple computer operation skills, including simple text input, application startup, simple file operation, and so on. What's more, they can also master the basic use of Windows operating system, Word and browser software.

Second, intermediate users of computers. This kind of students can use the Windows operating system skillfully, familiar with Word and browser software, but have little contact with Excel and PowerPoint, even if they have a little knowledge.

Third, skilled users of computers. This kind of students have received systematic computer skills training, and can skillfully use word, PowerPoint and other software. For these three types of students, different teaching contents were designed for them.

When we choose our teaching content, we should not be exhaustive, but boldly discard some outdated, unnecessary and tedious knowledge. In the process of practical teaching, we should make a choice of content and resolutely discard the unused content. For the above three types of students with different foundations, the following arrangements are made for the practical teaching contents:

(1) Basic teaching requirements. All students are required to master the basic operation of Windows, Word, Excel and PowerPoint after completing the training of basic computer skills. Students need to use Word to complete the arrangement of long documents skillfully, which lays a solid foundation for the subsequent paper writing and typesetting. It also requires skilled use of Excel to complete data statistics and processing, and skilled use of PowerPoint to design slides and text. The last requirement is to master the ability to use the Internet for information search.

(2) Expand teaching contents. For students with good foundation and strong ability, experimental contents of DreamWeaver, Visio and Flash were designed for them, enabling them to master these 
common tools and software through practical training courses and greatly improve their computer application skills.

In this way, through the arrangement of teaching contents, it can not only let students with poor foundation have a higher level of improvement, but also learn new knowledge for the top students. To some extent, it is beneficial to develop the potential of students to the maximum extent to improve the teaching quality of practical courses and ultimately promote the improvement of students' overall quality.

\subsection{Innovation and reform of teaching model}

First, the students' learning process is effectively monitored. The lack of monitoring of the learning process is a major problem caused by the expansion of college enrollment. And teachers have no ability to supervise students' learning process due to the large gap between students and teachers,. Many school-wide basic courses are seldom assigned after-class tasks, and teachers are difficult to comprehensively review, which greatly hinders the improvement of teaching quality. Based on this actual situation, we can fully exploit the laboratory resources, adopt the network homework method, require students to complete the required exercises within the specified time, and provide solutions and analysis when submitting. Such a solution not only saves the time for teachers to review and practice, but also objectively "supervise" students' extracurricular learning, so that the learning process control has rules to follow. Use new technologies such as online homework to enable students to learn outside of the classroom.

Second, in order to make full use of the experimental classroom, the measures that can be taken are: modify the experimental teaching materials, adopt the "task drive" teaching mode, design the basic operation training for each case and task, give a detailed operation steps in a graphic way, at the same time, make some appropriate comments on the knowledge which are involved in the progress of experiment, so that students can complete the experiment task and understand the knowledge in it by referring to the illustrations. Students can choose to do corresponding experiments according to their actual level. Teachers can follow the guidance of the classroom, answer questions, and it can focus on the explanation through the projector configured in the computer room to solve more problems, thus greatly improving the efficiency of the classroom.

By giving students more freedom in teaching, students can arrange their learning schedule according to their own situation, instead of being "all the same", so that students with different foundation can feel "fulfilled" and "have something to do" in the whole course teaching. To a large extent, this solves the objective difficulties brought by the differences of students' source base in organizing teaching.

\subsection{Innovation and reform of assessment methods}

In terms of examination, the traditional written examination and manual examination will be changed to fully implement the computerized examination and reading. It can greatly improve the efficiency of the whole assessment and make the assessment more objective. At the same time, this is also the technical guarantee of practical assessment. Otherwise, too much time for teachers to review papers will reduce the feasibility of teaching reform to a large extent. Using the paperless examination system can realize automatic paper formation, automatic paper reading and marking, and objectively and impartially evaluate students' computer application skills. The reform of examination method will bring direct economic benefits to the school: it greatly reduces the workload of the invigilator teachers, the input of the site, and the input of the test management personnel. It directly saves the printing and marking workload of paper examination papers.

\section{The significance of innovation and reform in practical teaching}

The innovation and reform of practical teaching can give play to the guiding role of teachers and improve their professional quality. In the process of teaching reform, teachers will find that their knowledge and teaching methods have gradually fallen behind the development needs of the times and cannot meet the needs of students and adapt to the development of contemporary society. This 
urges teachers to constantly enrich their knowledge structure, understand and master the latest trend of computer development, and infiltrate new knowledge and new cases into the daily teaching process.

The new practical teaching program requires students to complete a relatively independent work and task under the guidance of teachers. In the process of completion, students need to collect information, design the solution, implement the project and review the final work. In this way, through a comprehensive understanding of the whole process, students have a comprehensive understanding of this type of practical work, gain a further understanding of theoretical knowledge and operational skills, and experience the hardships and fun in the process of learning, which greatly improves students' practical ability and innovation ability.

\section{Conclusion}

With the rapid development of science and technology, computer plays an increasingly important role in people's life. The new practical teaching plan is based on the actual situation of colleges and universities and USES the computer practical teaching experience of other universities for reference. At the same time, the paper discusses the problems existing in computer application technology practice teaching in private colleges and proposes new innovative reform plan of practical teaching. The teaching takes the cultivation of application ability as the center and looks toward the high level of network and paperless. Therefore, it is one of the main tasks of colleges and universities to cultivate comprehensive talents with basic computer knowledge and basic skills. Combined with the needs of the times, the reform and innovation of computer application technology in colleges and universities is imperative to train computer talents who can keep pace with The Times.

\section{Acknowledgement}

This paper is derived from the 2017 scientific and technological research project of JiangXi provincial department of education, "research on computer application technology practice and innovation in private universities", project number: GJJ171043.

\section{References}

[1] Ming Li. Exploration and practice of university computer basic course reform [J]. Computer learning, 2010, 6.

[2] $\mathrm{Yu}$ Liang. Research on the teaching method of computer basic practice course [J]. Career education, 2011, 10.

[3] Ting Du. Teaching reform of computer basic practice courses for non-computer majors [J]. Criss-cross theory, 2011, 10. 